\title{
Implant Specialist
}

National Cancer Institute

\section{Source}

National Cancer Institute. Implant Specialist. NCI Thesaurus. Code C63741.

A dentist who specializes in surgical placement of dental implants or the restoration of dental implants in the facial bones. 